\title{
Evaluation of an individualised asthma programme directed at behavioural change
}

\author{
C. Put*, O. van den Bergh", V. Lemaigre* ${ }^{\#}$ M. Demedts*, G. Verleden*
}

Evaluation of an individualised asthma programme directed at behavioural change. C. Put, O.van den Bergh, V. Lemaigre, M. Demedts, G. Verleden. (C) ERS Journals Ltd 2003.

ABSTRACT: An individualised asthma programme directed at behavioural change was evaluated in asthmatic subjects who reported complaints and impairment, despite adequate medical treatment.

Mild-to-moderate asthma patients $(\mathrm{n}=\mathbf{2 3})$ were randomly assigned to a programme or waiting list condition. Outcome measures were: McMaster Asthma Quality of Life Questionnaire, Asthma Symptom Checklist, Negative Emotionality Scale, Knowledge, Attitude and Self-Efficacy Asthma Questionnaire, Adherence Scale, and peak flow measurements. Both groups were evaluated at three consecutive moments, each separated by 3 months; the programme was delivered between the first two evaluations. At onset the patient received a workbook containing information, exercises and homework assignments. Psycho-education, behavioural and cognitive techniques were introduced during six 1-h individual sessions.

Compared with controls the programme group reported less symptoms (obstruction, fatigue), better quality of life (activity, symptoms, emotions), decreased negative affectivity, and increased adherence, immediately after finishing the programme and at 3 months follow-up. All three cognitive variables (knowledge, attitude towards asthma, self-efficacy) and day and night peak flow ratings improved in the programme group but not in the waiting list group.

Participation in an individualised programme resulted in improvement of asthma morbidity, and asthma-related behaviour and cognitions, in subjects reporting symptoms and impairment despite adequate medical therapy.

Eur Respir J 2003; 21: 109-115.
*Dept of Respiratory Medicine, University Hospital Gasthuisberg, and

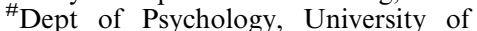
Leuven, Leuven, Belgium.

Correspondence: G. Verleden Dept of Respiratory Medicine University Hospital Gasthuisberg Herestraat 49

3000 Leuven

Belgium

Fax: 3216346803

E-mail: Geert.Verleden@uz.kuleuven. ac.be

Keywords: Asthma programme, behaviour, negative affectivity, self-management

Received: August 12001

Accepted after revision: August 62002

This study was supported by grants from the "Fonds voor Wetenschappelijk Onderzoek-Vlaanderen" (Grant 7.0004.000) and Astra Pharmaceuticals, Belgium.
In addition to pharmacological therapy, education and self-management have become indispensable aspects in the treatment of asthma. In order to assist patient and physician in the integration of medical and behavioural therapeutic instructions, self-management programmes were developed [1, 2]. By means of education and behavioural techniques, these programmes enhance the patient's sense of self-control, personal responsibility for the treatment, and consider physician and patient as partners in the management of asthma.

Several kinds of asthma programme have been developed, differing in terms of treatment components and outcome. Educating asthmatic subjects, or providing information on the pathophysiology of the illness and medication, results in increase of knowledge but not behavioural change nor decreased morbidity [3]. The development of step-care approaches to asthma management has been an important step towards simplification of asthma treatment. In this case, patients receive instructions consisting of treatment levels starting from baseline therapy, and ending up with consulting an emergency department, depending on the severity of their illness. The two most common elements of existing asthma programmes are education in addition to a self-management action plan for medication intake [4-6]. Therapeutic action plans can be based on changes in symptoms or changes in peakexpiratory flow rate (PEFR) [7-10]. In addition to self-management medical action plans and/or education, some programmes integrate other cognitivebehavioural techniques, such as relaxation training, cognitive restructuring, precipitant avoidance strategies, symptom management or stress-reduction techniques [11-14].

The current study assessed the efficiency of an individualised asthma programme for subjects who reported asthma symptomatology and impairment, despite adequate medical treatment. Whereas many asthma programmes seek to improve or change the patient's medical regimen with self-management techniques, this study sought to reinforce the prescribed therapy. By means of education, and cognitive and behavioural techniques, an attempt to change the patient's knowledge and attitude towards asthma, and asthma-related behaviour, such as symptomreporting, illness-related emotions, avoidance behaviour and nonadherence, was undertaken.

Another parameter that was included in this investigation was the trait "negative affectivity" (NA) or 
the disposition to experience subjective distress and dissatisfaction. NA has been extensively linked to illness behaviour and self-report of somatic symptoms. Generally, negative emotions seem to favour biased symptom perception in normals [15] and in asthma [16].

The authors' hypothesis was that education and cognitive-behavioural interventions would improve asthma-related behaviour, but not NA. Short-term therapy is known to influence affective behaviour in cases such as anxiety disorders [17], but the authors expected that the current interventions would be insufficient to change a disposition such as NA.

\section{Subjects and methods}

\section{Subjects}

Subjects $(n=101)$, who were part of an existing database of asthma patients, were invited by letter to participate in a study aimed at enhancing insight, decreasing symptoms and amelioration of impairment, associated with asthma. From the 101 invitations sent, 49 responses were received, and one envelope was returned unopened due to change of address.

Twenty-four subjects were uninterested, because of absence of complaints $(n=13)$, transportation difficulty $(n=6)$ and no time or interest $(n=5)$. Of the 49 responses, 25 subjects agreed to participate in the study. Informed consent was obtained from all patients. All subjects had been diagnosed with asthma by means of American Thoracic Society criteria, at least 6 months earlier [18]. Exclusion from the study was based on any of the following criteria: 1 ) aged $<18$ or $>65 \mathrm{yrs}$; 2) occupational asthma; 3) nicotine, drug or alcohol abuse; 4) absence of asthma symptoms during the last 6 months; 5) brittle asthma; and 6) previous participation in an educational or other asthma programme.

\section{Study design}

At the outpatient pulmonary clinic of the University Hospital Gasthuisberg, Leuven, Belgium, participating subjects were randomly allocated to either a programme group or a waiting list control group by means of the envelope technique. This randomisation method consists of drawing for each subject one unmarked, nontransparant envelope from a total of 23 envelopes (i.e. number of partcipants; 12 for treatment and 11 for control condition) containing the name of either condition. For both groups, outcome measurements were performed at three moments: baseline measurements were followed by two consecutive measurements, each with 3 months in-between. The programme was delivered to the treatment group between the first and second measurement. Two independent researchers were responsible for conducting the programme and for performing the measures. The person who collected the data was unaware of the condition each participant was assigned to.

\section{Outcome measures}

McMaster Asthma Quality of Life Questionnaire (AQLQ) [19] measures health-related limitations in quality of life experienced by asthmatic adults during the past 2 weeks. Thirty-two items fall into four domains: activity limitations (ACT), symptoms (SYM), emotions (EMO), and exposure to environmental stimuli. Item scores range from 1 (low quality of life) to 7 (high quality of life).

Asthma Symptom Checklist (ASC) [20, 21] contains 36 items and describes the subjective symptomatology of asthma. Six subscales comprise the ASC: symptoms of airway obstruction (OBS), dyspnoea, fatigue (FAT), symptoms suggestive of hyperventilation, anxiety, irritation (IRR). The patient indicates on a five-point scale the frequency of a symptom experienced during an asthma exacerbation ( $1=$ never, $5=$ =always).

Negative Emotionality Scale (NEM) [22] of 14 items measures negative affectivity as a personality trait, including a variety of negative emotional conditions, such as irritability, nervousness and emotional instability. Individual scores can range from 0 (low NA) to 14 (high NA).

The Adherence Scale [23] assesses the frequency of nonadherent behaviour during the last 3 months, by means of six items with a five-point rating scale (1=never, $5=$ very often). A decrease in scores signifies a decrease in nonadherent behaviour.

The Knowledge, Attitude and Self-Efficacy Asthma Questionnaire (KASE-AQ) [24] consists of three subscales of 20 items and assesses patients' knowledge regarding asthma ("knowledge": individual scores range $0-20$ ), attitude towards the illness and selfefficacy regarding the perceived ability to control the disorder ("attitude" and "self-efficacy": minimum score $=20$, maximum score $=100$ ).

PEFR were measured by the subjects at home twice daily (morning and evening) during 14 consecutive days. Each time three manoeuvres were recorded on separate assessment sheets.

\section{Procedure and programme interventions}

Before randomisation and before signing informed consent, patients received information about the procedure of allocation (timing of programme participation is unknown upfront), content (programme provides asthma-related information, teaches techniques to manage asthma-related symptoms and impairment), and the importance of the patients' own input (homework assignments). At onset of the programme, participants received a workbook, with information, exercises and homework assignments, presented in a clear and comprehensible manner. During six 1-h individual programme sessions different strategies were employed [2, 24-26].

Psycho-education. The patients' personal illness representations, or their cognitions regarding origin, symptoms, course and therapy of their illness, were identified and information about the pathophysiology of asthma, 
mechanisms of medication, eliciting factors etc. was provided in an interactive way.

Behavioural techniques. Behavioural techniques such as self-monitoring/self-observation, stimulus control, and response control were taught.

Self-observation/self-monitoring. Patients registered daily qualitative and quantitative aspects of asthma complaints (ASC, intensity from $0-10$ ), in addition to medication use, specific eliciting factors, and subsequent behavioral responses. In this way (in)adequate ways of dealing with asthma were linked to specific antecedents or consequences.

Stimulus control. Stimulus control refers to the change of the behaviour antecedents, either by eliminating stimuli with a negative influence (e.g. specific environmental stimuli in case of allergic asthma) or by introducing appropriate stimuli that elicit desired behaviour (e.g. putting medication in a visible place).

Response control. Response control entails the behavioural control of the consequences, or of the influence of eliciting factors. The patient learns to select the appropriate behaviour to avoid or minimise the influence of stimuli, by considering the behaviours' long- versus short-term consequences. For instance, at one time point medication intake can have a short-term negative consequence (interruption of activity) or long-term positive effects (less exacerbations).

Cognitive techniques. Cognitive techniques teach the patient to identify negative and irrational cognitions regarding asthma and asthma therapy, and their influence on emotions and behaviour. By means of cognitive restructuring these cognitions are questioned and corrected.

In addition to a standard programme formula, intervention "modules" were presented when indicated. This implied that, whenever problem areas, such as disease-specific anxiety, were identified in consideration with the patient, certain parts of the training programme were elaborated upon.

\section{Analysis}

For dichotomous measures, contingency table analysis was used to evaluate group differences, and significance was assessed using the Chi-squared test. Group data were summarised as mean \pm SD. The programme impact for the two groups was assessed by repeated measures analysis of variance, at three consecutive measure measurements (baseline, after programme, follow-up). For all outcome parameters, within-subject pairwise comparisons (paired t-test) were carried out when the analysis had revealed a significant group $\times$ measurement interaction effect with the $\alpha$-level set at 0.05 . Differences between conditions at baseline were investigated by means of the unpaired t-test.

\section{Results}

\section{Subjects' characteristics}

From the treatment group, one subject dropped out after onset of the programme, (organisational incompatibility with professional situation), and from the waiting list group, not all the data were collected for one subject. Eventually, 23 subjects were included in the study: 12 subjects in the treatment group, and 11 subjects in the control group.

Baseline characteristics are presented in table 1. The control group was prescribed more anticholinergics than the intervention group (Chi-squared $=5.3, p=0.02$ ); both conditions did not differ regarding other characteristics. Asthma severity was equal for both groups, only one subject was categorised as severely asthmatic.

\section{Programme efficiency}

At baseline there were no significant differences between the two conditions, for any of the outcome measures. For three of the AQLQ subscales there was a group $\times$ measure moment interaction effect: ACT $(\mathrm{F}(2,42)=27.2, \mathrm{p}<0.0001), \operatorname{SYM}(\mathrm{F}(2,42)=15.9)$, and EMO $(\mathrm{F}(2,42)=6.4, \mathrm{p}<0.005$; table 2$)$. For each of these AQLQ subscales, the experimental group demonstrated an increase in quality of life between the first and second measurement (ACT: $\mathrm{t}(11)=-4.9$, $\mathrm{p}=0.0005$; SYM: $\mathrm{t}(11)=-7.7, \mathrm{p}<0.0001$; EMO: $\mathrm{t}(11)=$ $-4.7, p<0.001)$. Between the second and third measurement, there was a further increase for ACT $(\mathrm{t}(11)=-2.6, \mathrm{p}<0.05)$ but for SYM and EMO there

Table 1.-Demographic and clinical characteristics in an intervention and waiting list group at baseline

Intervention Waiting list

\begin{tabular}{lcc}
\hline Subjects n & 12 & 11 \\
Males n (\%) & $7(58)$ & $4(38)$ \\
Age yrs & $43 \pm 10$ & $48 \pm 12$ \\
Duration of symptoms yrs & $9 \pm 6$ & $12 \pm 8$ \\
FEV1 & $2.8 \pm 0.7$ & $2.6 \pm 0.6$ \\
$\quad$ L & $85 \pm 20$ & $90 \pm 12$ \\
$\quad \%$ pred & & \\
FVC & $3.9 \pm 0.9$ & $3.8 \pm 0.8$ \\
$\quad$ L & $99 \pm 14$ & $108 \pm 10$ \\
$\quad \%$ pred & & \\
Prescribed medication & $4.7 \pm 4.2$ & $4.1 \pm 3.0$ \\
$\quad$ Inhaled $\beta_{2}$-agonists puffs $\cdot$ day $^{-1}$ & $1354 \pm 607$ & $1059 \pm 424$ \\
$\quad$ Inhaled steroids $\mu \mathrm{g} \cdot$ day $^{-1}$ & 5 & 2 \\
Theophyllines n & 2 & 4 \\
Cromoglycate $\mathrm{n}$ & 1 & 2 \\
Oral steroids n & 0 & 4 \\
Anticholinergics n & & \\
Asthma severity n & 4 & 3 \\
$\quad$ Mild & 7 & 8 \\
$\quad$ Moderate & 1 & 0 \\
$\quad$ Severe & &
\end{tabular}

Data are presented as mean $\pm \mathrm{SD}$, unless otherwise stated. FEV1: forced expiratory volume in one second; FVC: forced vital capacity. \#: significant difference between both groups. 
Table 2. - Influence of an asthma programme on outcome variables compared with a waiting list condition

\begin{tabular}{|c|c|c|c|c|c|c|c|}
\hline & \multicolumn{3}{|c|}{ Treatment group } & \multicolumn{3}{|c|}{ Waiting list } & \multirow[t]{2}{*}{ p-value ${ }^{\#}$} \\
\hline & First & Second & Third & First & Second & Third & \\
\hline \multicolumn{8}{|l|}{ AQLQ } \\
\hline Activity level & $4.9 \pm 0.9$ & $5.6 \pm 0.8^{\bullet}$ & $5.9 \pm 0.6^{\oplus}$ & $4.7 \pm 0.9$ & $4.4 \pm 0.7$ & $4.5 \pm 0.5$ & $<0.0001$ \\
\hline Symptoms & $4.5 \pm 0.9$ & $5.5 \pm 0.6$ & $5.3 \pm 1.0$ & $5.0 \pm 0.9$ & $4.8 \pm 0.7$ & $5.0 \pm 0.7$ & $<0.0001$ \\
\hline Emotions & $4.9 \pm 1.2$ & $6.1 \pm 0.7^{\bullet}$ & $6.1 \pm 0.8$ & $4.7 \pm 1.6$ & $4.8 \pm 1.0$ & $5.0 \pm 0.9$ & 0.003 \\
\hline Environment & $5.1 \pm 1.7$ & $5.7 \pm 1.1$ & $5.6 \pm 1.2$ & $4.9 \pm 1.4$ & $5.0 \pm 0.8$ & $5.1 \pm 0.8$ & NS \\
\hline Total & $4.8 \pm 1.0$ & $5.7 \pm 0.6^{\bullet}$ & $5.7 \pm 0.7$ & $4.8 \pm 1.1$ & $4.7 \pm 0.7$ & $4.9 \pm 0.6$ & $<0.0001$ \\
\hline \multicolumn{8}{|l|}{ ASC } \\
\hline Obstruction & $3.0 \pm 0.8$ & $2.4 \pm 0.9$ & $2.5 \pm 0.8$ & $3.3 \pm 0.9$ & $3.2 \pm 0.8$ & $3.2 \pm 1.1$ & 0.04 \\
\hline Dyspnoea & $3.4 \pm 1.1$ & $3.1 \pm 1.1$ & $3.3 \pm 1.2$ & $3.8 \pm 0.9$ & $3.5 \pm 0.8$ & $3.6 \pm 1.0$ & NS \\
\hline Fatigue & $2.7 \pm 0.9$ & $2.0 \pm 0.8$ & $2.0 \pm 0.8$ & $3.2 \pm 1.2$ & $3.2 \pm 1.1$ & $3.1 \pm 1.2$ & 0.001 \\
\hline Hyperventilation & $1.8 \pm 0.6$ & $1.5 \pm 0.7$ & $1.5 \pm 0.3$ & $2.1 \pm 0.8$ & $2.0 \pm 0.8$ & $1.8 \pm 0.7$ & NS \\
\hline Anxiety & $1.9 \pm 0.6$ & $1.6 \pm 0.8$ & $1.8 \pm 0.8$ & $2.6 \pm 1.2$ & $2.6 \pm 1.2$ & $2.5 \pm 1.1$ & NS \\
\hline Irritation & $2.5 \pm 1.0$ & $1.9 \pm 0.9$ & $2.0 \pm 0.6$ & $2.4 \pm 1.0$ & $2.4 \pm 0.9$ & $2.5 \pm 1.1$ & 0.03 \\
\hline \multicolumn{8}{|l|}{$\mathrm{KASE}^{-\mathrm{AQ}^{+}}$} \\
\hline Knowledge $(n=9)$ & $11.8 \pm 2.6$ & $15.6 \pm 0.8^{\pi}$ & $16.4 \pm 0.5^{\oplus}$ & $11 \pm 2.5$ & $11.5 \pm 2.6$ & $12 \pm 2.6$ & 0.008 \\
\hline Attitude $(n=17)$ & $77 \pm 4$ & $88 \pm 4$ & $88 \pm 6$ & $76 \pm 5$ & $74 \pm 4$ & $77 \pm 5$ & $<0.0001$ \\
\hline Self-efficacy $(n=21)$ & $71 \pm 8$ & $86 \pm 11^{\top}$ & $85 \pm 10$ & $67 \pm 9$ & $66 \pm 8$ & $68 \pm 5$ & $<0.0001$ \\
\hline \multicolumn{8}{|l|}{$\operatorname{PEFR}^{+}(\mathrm{n}=22)$} \\
\hline Day $L \cdot \min ^{-1}$ & $410 \pm 90$ & $430 \pm 93^{\top}$ & $423 \pm 93$ & $403 \pm 90$ & $398 \pm 82$ & $398 \pm 90$ & 0.03 \\
\hline Night $L \cdot \min ^{-1}$ & $400 \pm 81$ & $423 \pm 81^{\bullet}$ & $415 \pm 90$ & $383 \pm 105$ & $375 \pm 103$ & $380 \pm 95$ & 0.04 \\
\hline NEM & $5.2 \pm 3.3$ & $2.4 \pm 2.6$ & $2.7 \pm 2.9$ & $6.7 \pm 2.9$ & $7.1 \pm 2.9$ & $6.4 \pm 2.9$ & 0.0002 \\
\hline Adherence Scale & $9.7 \pm 2.0$ & $7.0 \pm 1.6^{\circ}$ & $6.9 \pm 1.2$ & $8.2 \pm 2.3$ & $8.4 \pm 2.1$ & $8.1 \pm 3.1$ & 0.002 \\
\hline
\end{tabular}

First: baseline measurement; Second: waiting list group measurement 3 months after baseline, for treatment group immediately after programme interventions; Third: waiting list group measurement 6 months after baseline, for treatment group follow-up at 3 months after interventions. AQLQ: asthma quality of life questionnaire; ASC: asthma symptom checklist; KASE-AQ: knowledge, attitude and self-efficacy asthma questionnaire; PEFR: peak-expiratory flow rate; NEM: negative emotionality score; NS: nonsignificant. ${ }^{\#}$ : analysis of variance; ${ }^{\uparrow}$ : paired t-test indicated significant difference with mean score of previous measurement within same condition; ${ }^{+}$: cases missing.

were no differences. In the control group, no differences between successive measurements were reflected, except for ACT, in which a decrease in quality of life was observed between the first and second measurement $(\mathrm{t}(10)=2.9, \mathrm{p}=0.01)$.

In three ASC subscales, an interaction between condition and measurement was present: $\mathrm{OBS}(\mathrm{F}(2,42)=$ $3.3, \mathrm{p}<0.05)$, FAT $(\mathrm{F}(2,42)=7.9, \mathrm{p}=0.001)$, and IRR $(\mathrm{F}(2,42)=3.8, \mathrm{p}<0.05)$. For these three subscales, the treatment group reported a decrease of symptoms after the intervention and this was maintained at 3 months; there were no changes in the control group for any of these three measurements.

Throughout the three measurements, the control group had higher NEM-scores than the treatment group $(F(1,21)=8.1, p<0.01)$; there was also a group $\times$ measure moment interaction for NA: in the treatment subjects a decrease in NEM scores was observed after the interventions $(\mathrm{F}(2,42)=10.8, \mathrm{p}=0.0002)$ and this level was maintained at 3 months. In the control subjects over the three measurements no changes were recorded.

Adherence Scale scores decreased significantly in the treatment group immediately after programme interventions and these scores remained the same at 3 months evaluation $(\mathrm{F}(2,42)=6.8, \mathrm{p}<0.005)$, whereas there were no differences in controls between the three consecutive measurements.

For all KASE-AQ subscales there were missing data, with samples ranging from $n=9$ (Knowledge), $n=17$ (Attitude), to $n=21$ (Self-efficacy). Despite these reduced numbers, there was a significant interaction effect between condition and measurement for all subscales of the KASE-AQ. Knowledge: $F(2,14)=6.8$, $\mathrm{p}<0.01$; Attitude: $\mathrm{F}(2,30)=22.4, \mathrm{p}<0.0001$; Selfefficacy: $\mathrm{F}(2,38)=20.7, \mathrm{p}<0.0001$. In the treatment group, a significant increase in all three subscales was observed between the first and second measurements (Knowledge: $\mathrm{t}(5)=-2.9, \mathrm{p}<0.05$; Attitude: $\mathrm{t}(8)=-7.9$, $\mathrm{p}<0.0001$; Self-efficacy: $\mathrm{t}(11)=-6.7, \mathrm{p}<0.0001)$; this was not the case for the control group. Between the second and third measurements, there were no differences observed, except for an increase in Knowledge $(\mathrm{t}(6)=-2.8, \mathrm{p}<0.05)$.

Both for day and night PEFRs $(n=22$, the data of one programme group subject were incomplete), there was an increase in the treatment group between the first and second measurements (day, condition $\times$ measurement: $\mathrm{F}(2,40)=3.8, \mathrm{p}=0.02$ and $\mathrm{t}(11)=-2.6$, $\mathrm{p}<0.05$; night, condition $\times$ measurement: $\mathrm{F}(2,40)=3.3$, $\mathrm{p}<0.05$ and $\mathrm{t}(11)=-3.2, \mathrm{p}<0.01)$. Between the second and third measurements, there was a nonsignificant tendency to decrease for night and day PEFR in the treatment group. In the control group, there were no differences between the three measurements.

\section{Discussion}

The efficiency of an individualised asthma programme that aimed to reduce asthma symptoms and impairment was investigated. Compared with waiting 
list patients, the subjects who had participated in the programme reported significant improvement in quality of life, asthma symptoms, compliance, PEFR, knowledge, attitude towards asthma, self-efficacy, and negative emotionality. All improvements were visible immediately after the programme interventions and were sustained at 3 months follow-up.

As with other studies [5, 9, 11], the authors found an improvement in disease-specific quality of life after participation in an asthma self-management programme. Specifically, the treatment group reported less impairment, less respiratory symptoms, and less asthma-related emotionality immediately after the programme and after 3 months. Interestingly, although subjects in this sample were classified as having mildto-moderate asthma, the total AQLQ data were similar to the data of moderate to moderately severe asthma subjects [9]. The slightly higher mean age and impairment, as part of the inclusion criteria of this sample, might explain this observation.

The observed short- and long-term influence of education, embedded in an asthma self-management programme on knowledge was extensively demonstrated previously $[7,12]$. Interestingly, subjects reported increased knowledge 3 months after finishing the programme, in addition to an immediate programme effect. One plausible explanation is the continuous consultation of the workbook even after completion of the programme, resulting in further consolidation of knowledge. In contrast with knowledge, other cognitive variables such as self-efficacy and attitude towards the illness, have been included less frequently as outcome variables for the efficiency of an asthma programme. However, there is substantial evidence that both factors are important intermediate variables for change of health-related behaviour [27, 28]. SNYDER et al. [29] found increased knowledge in the treatment group relative to the waiting list group, but no changes were reported regarding attitude about asthma and self-efficacy. The present programme induced improvement in self-efficacy and asthmarelated attitude. For two out of the three cognitive parameters there was a large amount of missing cases. Since this was not observed for other outcome measures, the cause for this remains unclear. It is unlikely that the high rate of missing cases rendered the current results misleading, since it occurred equally in both groups.

The programme had a significant effect on asthma morbidity. After the programme interventions, less symptoms of airway obstruction, fatigue and irritation were reported, and both day and night-time PEFR increased significantly. These improvements could not be attributed to changes in therapeutic regimen. The strategy for this programme was to emphasise the existing regimen, since all patients had previously received adequate instructions on pharmacological asthma management. One factor that might have contributed to improved asthma morbidity was the increased compliance with medication intake.

Similarly to other studies on asthma self-management $[12,13]$, compliance with medical therapy increased after programme participation. The overall level of adherence in this study was good: only two subjects dropped out of the study, and a higher cooperation with PEFR monitoring, than could be expected, was observed [30]. One reason for this generally high adherence rate was the individualised nature of the programme, meaning that great effort was taken to meet the patient's needs and priorities. Secondly, during recruitment, only the subjects who were motivated to participate in the study and for whom the description of the programme was appealing, might have responded positively to the invitation letter.

Negative affectivity can be measured as a trait and as a state. Correlations between state and trait measures are high [31]. In this study NA was measured at the trait level, implying that it referred to a stable, consistent and persistent characteristic. Nevertheless, the subjects reported less trait NA after they had participated in an asthma management programme, which was not observed in a group that had not been subjected to the programme. Personality, as a construct, has a stable enduring aspect, which is resistant to therapy, but on the other hand there is a dynamic, changeable aspect on the level of symptoms and behaviours [32]. This was shown in one study where no intra-individual changes in trait NA were found, despite a significant improvement in the clinical condition and quality of life of asthmatic subjects [16]. However, the significant correlations between changes in emotional trait and changes in emotional states in the current study ( $\mathrm{r}$ between $0.50-0.62, \mathrm{p}<0.01)$ highlighted the variable aspect of trait NA. Additionally, cognitive-behavioural interventions have been proven effective treatment to alleviate symptoms and reduce symptomatic behaviour, both of which accompany personality disorders [33].

Unlike other studies, this programme recruited subjects who experienced asthma symptoms and impairment, despite seemingly adequate medical treatment. Mostly, the samples selected for studies on programme efficiency consist of asthmatic subjects with moderate-to-severe asthma, because they are considered as a high-risk population [7, 11, 12, 14, 30]. Other examples of target population are minority groups, such as African-Americans, the Hispanic population, or people with socioeconomic problems and low education [34-37]. Common to these patient groups is that their asthma was not adequately controlled for by medication at the onset of the study. Thus, the improvements that are generally observed can be attributed to better medical management due to the introduction of self-management training. Instead, this study included patients with mild-to-moderate asthma who complained and reported impairment, despite their clinically stabilised condition and an appropriate medical regimen. They were considered to be a relevant group because they are often a challenge in clinical practice and induce a considerable amount of frustration to their treating physician. The application of new behavioural strategies to deal with asthma has yielded positive changes in cognitive, behavioural, affective and respiratory parameters. KoTSES et al. [38] have obtained similar results in patients with moderate-to-severe asthma 
who had received appropriate medical attention before they entered the study.

The study described here concerns an individualised asthma-training programme. Although the authors are unable to give an exact cost estimation of the programme, it might be fairly expensive: $6 \mathrm{~h}$ of training per patient plus additional administrative time arranging appointments. However, when considering the cost-effectiveness of the training programme at least two factors need to be considered: 1) the target group for this study (patients reporting complaints and impairment despite a medically satisfactory condition), is indeed not a high-risk population, which would justify the high costs. This particular clinical condition can lead to "doctor shopping" or repeated medical consultations and requests for tests and examinations. In this way the programme has indirect economic benefits. 2) In the current template, the programme was administered by a psychologist, but to become more cost-effective, other paramedical disciplines could be trained to deliver the programme.

A major limitation of this study was that only results at 3 months follow-up could be reported, while in other studies, follow-up measurements were performed at 6 months and even 12 months or 6 yrs after the intervention. Subjects were able to maintain the increases in knowledge and quality of life for up to $1 \mathrm{yr}$ after completion of the programme [7, 11]. Asthma morbidity increased once self-management behaviour and adherence to original programme instructions deteriorated, due to lack of reinforcement of self-management skills [39].

To conclude, participation in an asthma programme consisting of education and asthma-specific cognitive-behavioural interventions resulted in decreased asthma morbidity, improved health-related quality of life, enhanced compliance, increased knowledge and self-efficacy, a more positive attitude towards asthma, and a general feeling of less negativity. Although followup data did not reach beyond 3 months, these findings might be promising for a seldom-addressed population of subjects reporting symptoms and impairment, despite a clinically satisfactory condition.

\section{References}

1. Lehrer PM, Sargunaraj D, Hochron S. Psychological approaches to the treatment of asthma. J Consult Clin Psychol 1992; 60: 639-643.

2. Creer TL, Winder JA. The self-management of asthma. In: Holroyd KA, Creer TL, eds. Handbook of Self-Management in Health Psychology and Behavioral Medicine. New York, Plenum Press, 1986; pp. 269-303.

3. Hilton S, Sibbald B, Anderson HR, Freeling P. Controlled evaluation of the effects of patient education on asthma morbidity in general practice. Lancet 1986; 1: 26-29.

4. Gibson PG, Coughlan J, Wilson AJ, et al. Selfmanagement education and regular practitioner review for adults with asthma. CD001117. Cochrane Database System Review 2000.
5. Gallefoss F, Bakke PS, Rsgaard PK. Quality of life assessment after patient education in a randomized controlled study on asthma and chronic obstructive pulmonary disease. Am J Respir Crit Care Med 1999; 159: 812-817.

6. Gallefoss F, Bakke PS. How does patient education and self-management among asthmatics and patients with chronic obstructive pulmonary disease affect medication? Am J Respir Crit Care Med 1999; 160: 2000-2005.

7. Cote J, Cartier A, Robichaud P, et al. Influence on asthma morbidity of asthma education programs based on self-management plans following treatment optimization. Am J Respir Crit Care Med 1997; 155: 1509-1514.

8. Cowie RL, Revitt SG, Underwood MF, Field SK. The effect of a peak flow-based action plan in the prevention of exacerbations of asthma. Chest 1997; 112: 1534-1538.

9. Turner MO, Taylor D, Bennett R, Fitzgerald JM. A randomized trial comparing peak expiratory flow and symptom self-management plans for patients with asthma attending a primary care clinic. Am J Respir Crit Care Med 1998; 157: 540-546.

10. Lopez-Vina A, Castillo-Arevalo E. Influence of peak expiratory flow monitoring on an asthma self-management education programme. Respir Med 2000; 94: 760-766.

11. Lahdensuo A, Haahtela T, Herrala J, et al. Randomised comparison of guided self management and traditional treatment of asthma over one year. $B M J$ 1996; 312: 748-752.

12. Allen RM, Jones MP, Oldenburg B. Randomised trial of an asthma self-management programme for adults. Thorax 1995; 50: 731-738.

13. Bailey WC, Richards JM, Brooks CM, Soong SJ, Windsor RA, Manzella BA. A randomized trial to improve self-management practices of adults with asthma. Arch Intern Med 1990; 150: 1664-1668.

14. Wilson SR, Scamagas P, German DF, et al. A controlled trial of two forms of self-management education for adults with asthma. Am J Med 1993; 94 : 564-576.

15. Stegen K, Neujens A, Crombez G, Hermans D, Van de Woestijne KP, van den Bergh O. Negative affect, respiratory reactivity, and somatic complaints in a $\mathrm{CO}_{2}$ enriched air inhalation paradigm. Biol Psychol 1998; 49: 109-122.

16. Put C, Demedts M, van den bergh O, Demyttenaere $\mathrm{K}$, Verleden G. Asthma symptoms: influence of personality versus clinical status. Eur Respir J 1999; 13: 751-756.

17. Suinn RM. Anxiety Management Training. A Behavior Therapy. New York, Plenum Press, 1990.

18. National Heart, Lung and Blood Institute. Guidelines for the diagnosis and management of asthma. National Asthma Education Program. Expert Panel report. J Allergy Clin Immunol 1991; 88: 425-534.

19. Juniper EF, Guyatt GH, Epstein RS, Ferrie PJ, Jaeschke R, Hiller TK. Evaluation of impairment of health related quality of life in asthma: development of a questionnaire for use in clinical trials. Thorax 1992; 47: 76-83.

20. Kinsman RA, Luparello T, O'Banion K, Spector S. Multidimensional analysis of the subjective symptomatology of asthma. Psychosom Med 1973; 35: 250267. 
21. Brooks CM, Richards JM, Bailey WC, Martin B, Windsor RA, Soong SJ. Subjective symptomatology of asthma in an outpatient population. Psychosom Med 1989; 51: 102-108.

22. Tellegen A, Lykken DT, Bouchard TJ, Wilcox KJ, Segal NL, Rich S. Personality similarity in twins reared apart and together. J Pers Soc Psychol 1988; 54: 1031-1039.

23. Brooks CM, Richards JM, Kohler CL, et al. Assessing adherence to asthma medication and inhaler regimens: a psychometric analysis of adult self-report scales. Med Care 1994; 32: 298-307.

24. Wigal JK, Stout C, Brandon M, et al. The Knowledge, Attitude, and Self-Efficacy Asthma Questionnaire. Chest 1993; 104: 1144-1148.

25. Kendall PC, Hollon SD. Cognitive-Behavioural Interventions: Theory, Research and Procedures. New York, Academic Press, 1979.

26. Kotses H, Lewis P, Creer TL. Environmental control of asthma self-management. J Asthma 1990; 27: 375384.

27. O'Leary A. Self-efficacy and health. Behav Res Ther 1985; 23: 437-451.

28. Tobin DL, Wigal JK, Winder JA, Holroyd KA, Creer TL. The "Asthma Self-Efficacy Scale". Ann Allergy 1987; 59: 273-277.

29. Snyder SE, Winder JA, Creer TL. Development and evaluation of an adult asthma self-management program: Wheezers Anonymous. J Asthma 1987; 24: 153-158.

30. Cote J, Cartier A, Malo JL, Rouleau M, Boulet LP. Compliance with peak expiratory flow monitoring in home management of asthma. Chest 1998; 113: 968972.

31. Wientjes CJ, Grossman P. Overreactivity of the psyche or the soma? Interindividual associations between psychosomatic symptoms, anxiety, heart rate, and end-tidal partial carbon dioxide pressure. Psychosom Med 1994; 56: 533-540.

32. Clarkin JF, Lenzenweger MF. Major theories of personality disorder. In: Pretzer JL, Beck JC, eds. A Cognitive Theory of Personality Disorders. New York, Plenum Press, 1996; pp. 36-105.

33. Sanislow CA, McGlashan TH. Treatment outcome of personality disorders. Can J Psychiatry 1998; 43: $237-$ 250.

34. D'Souza W, Crane J, Burgess C, et al. Communitybased asthma care: trial of a "credit card" asthma selfmanagement plan. Eur Respir J 1994; 7: 1260-1265.

35. Hendricson WD, Wood PR, Hidalgo HA, et al. Implementation of individualized patient education for Hispanic children with asthma. Patient Educ Couns 1996; 29: 155-165.

36. Legorreta AP, Christian-Herman J, O'Connor RD, Hasan MM, Evans R, Leung KM. Compliance with national asthma management guidelines and specialty care: a health maintenance organization experience. Arch Intern Med 1998; 158: 457-464.

37. de Oliveira MA, Bruno VF, Ballini LS, BritoJardim JR, Fernandes AL. Evaluation of an educational program for asthma control in adults. J Asthma 1997; 34: 395-403.

38. Kotses H, Bernstein IL, Bernstein DI, et al. A selfmanagement program for adult asthma. Part I: Development and evaluation. J Allergy Clin Immunol 1995; 95: 529-540.

39. D'Souza WJ, Slater T, Fox C, et al. Asthma morbidity 6 yrs after an effective asthma self-management programme in a Maori community. Eur Respir $J$ 2000; 15: 464469. 